\title{
Sobre el debate entre arquitectos profesionales y arquitectos artistas en el barroco madrileño. Las posturas de Herrera, Olmo, Donoso y Ardemans
}

\author{
Beatriz Blasco Esquivias *
}

" $i E l$ diablo tiene esta pintura en el cuerpo! Porque si he querido ser geómetra, lo he conseguido; si aritmético, también; si arquitecto, lo mismo; $y$ en este diablo de la Pintura, con tanto como me he desvelado en ella, voto a $N$. que aún no sé dibujar un ojo".

Quien asi hablaba, con palabras puestas en su boca por Antonio Palomino, era don Francisco de Herrera, hombre al parecer arrogante que, a pesar de sus falsas lamentaciones, no sólo disfrutó de los principales cargos a que podía aspirar un Arquitecto en los círculos cortesanos, sino que también obtuvo el máximo reconocimiento oficial como Pintor, satisfaciendo una aspiración que muy pocos pudieron cumplir durante nuestra Historia Moderna. Palomino admiró su ingenio y su apostura y, aunque no pudo obviar ciertos rasgos endiablados de su carácter al trazar su biografía, rindió el homenaje merecido a su talento, proporcionándonos jugosas noticias sobre su trayectoria vital y artística, así como algunas informaciones inexactas ${ }^{1}$. De entre todas, la que nos interesa

* Universidad Complutense de Madrid.

- La cita está tomada de Palomino, A., Vidas. Madrid 1986, pág. 284. La biografía de Herrera se localiza en las páginas 280-284. 
ahora es la relativa a su paso por la Maestria Mayor de Obras Reales, empleo que, según el de Bujalance, obtuvo tras la muerte de Sebastián Herrera Barnuevo, en 1671. Hay que esperar hasta la publicación del Diccionario de Ceán para saber que no fue a Barnuevo sino a Gaspar de la Peña a quien sustituyó "el Mozo" en el empleo citado, y que no fue en 1671 sino en el 77 cuando se produjo el relevo ${ }^{2}$. El propio Ceán, tan excesivo siempre en los comentarios y juicios que formuló contra los "excesos" del Barroco, repitió este dato al ampliar el manuscrito de Llaguno, pero alertado por las noticias de don Eugenio sobre la resolución de la vacante de Barnuevo y sobre el acceso de José del Olmo a la maestría en 1677, trató de conjugar ambos supuestos concluyendo "que hubo a un tiempo dos maestros mayores, a saber, Francisco de Herrera, sucesor de Gaspar de la Peña, nombrado en 25 de agosto de 1677, y Josef del Olmo en 3 de setiembre del mismo año, pero sin sueldo, que no gozó hasta la muerte de Herrera" ${ }^{3}$.

De ser así, nos encontraríamos ante un caso verdaderamente atípico y excepcional en la historia de los empleos adscritos a Obras Reales, aunque la realidad es muy distinta. En las páginas siguientes nos ocuparemos del controvertido y largo proceso que se siguió en la Corte para proveer la vacante de Gaspar de la Peña, un proceso en el que se vieron involucrados, entre otros, el propio Francisco de Herrera, José Jiménez Donoso, el joven Teodoro Ardemans y José del Olmo, uno de los principales protagonistas del caso, cuya fama quedó malparada durante algún tiempo.

Aunque no podemos detenernos ahora en analizar la categoria artística de Olmo, sí podemos señalar que se trata de uno de los arquitectos más destacados del momento, no sólo por la entidad de las obras que realiza, sino por la relevancia de los empleos oficiales que detentó a lo largo de su vida. Fue además un personaje controvertido, que despertó firmes apoyos y también acendrados odios; que estuvo tan ligado a la persona de don Fernando Valenzuela que fue arrastrado en su caida y dio con sus huesos en la cárcel; que intervino activamente en alguna de las revueltas sociales producidas al final del reinado de Carlos II, cuando los tumultos populares contra Oropesa determinaron la caida del ministro

2 Bermúdez, Ceán, Diccionario histórico de los más ilustres profesores de las Bellas Artes de España. Madrid 1800, t. II, pág. 281: “... También le nombró el rey maestro mayor de las obras reales el año de 677 por muerte de Gaspar de la Peña, y no en 71 , ni por fallecimiento de D. Sebastián de Herrera, como dice Palomino...".

${ }^{3}$ Llaguno, E., y Cean Bermudez, A., Noticias de los Arquitectos y Arquitectura de España desde su restauración. Madrid, s.a., ed. de Madrid, 1977, t. IV, págs. 78-79. 
y su destierro; que mantuvo una decidida y combativa postura contra la intromisión de los pintores en el ejercicio de la arquitectura, y, en fin, que, fruto de todo ello, fue una carrera profesional salpicada de éxitos y de fracasos como el que constituyó que Carlos II dejara sin efecto su nombramiento de Maestro Mayor de Obras Reales en 1677 para concedérselo a Francisco de Herrera ${ }^{4}$.

Los hechos transcurrieron de la siguiente forma. Tras la muerte de Gaspar de la Peña, el uno de junio de 1676, se procedió a concursar su vacante siguiendo los procedimientos habituales. Por aquellos años vivia don Fernando Valenzuela uno de los momentos mas esplendorosos de sus fulgurante y discutida carrera cortesana, al amparo de la reina madre, $y$, además de otros muchos honores que escandalizaron a algunos de los grandes linajes españoles, habia conseguido de doña Mariana el nombramiento de Superintendente de Obras Reales en enero de $1675^{5}$. Respaldado por la nueva fuerza adquirida, el valido no dudó en desafiar la autoridad de la poderosa Junta de Obras y Bosques y, además de suspender los oficios de Veeduría y Contaduría y de Pagaduría de Obras Reales, aprovechó la vacante de la maestría mayor para que triunfara la candidatura de su protegido, el aparejador segundo José del Olmo, consiguiendo que el joven rey Carlos expidiera una cédula de nombramiento

${ }^{4}$ La personalidad humana y artistica de Olmo está aún sin estudiar en profundidad, aunque bien lo mereceria. Una primera aproximación a su vida y a su obra en Tovar, $V$., Arquitectos madrileños de la segunda mitad del siglo xvil. Madrid 1975, págs. 225-252. Por ella conocemos los sucesos más importantes que vertebraron su biografia, sabemos de su enemistad con algunos colegas, como Bartolomé Hurtado, asi como del suceso que le llevó a la cárcel por abrazar la causa de Valenzuela en un momento desfavorable para el valido, cuando se produjo su caida política. Además de estos datos, y de los que vamos a ir ofreciendo en las páginas siguientes, queremos dar a conocer la existencia de una vehemente arenga de Olmo al "gremio de albañiles" y al pueblo madrileño contra los abusos que estaban cometiendo la reina y su camarilla, al final de la vida y del reinado de Carlos II. Está encabezada por las siguientes palabras “Noble exortación, que Joseph del Olmo, Maestro Mayor de Palacio hizo a los esforzados de su Gremio, y Pueblo de Madrid el dia 10 del mes de Abril, del año de 1699"; la fecha debe estar equivocada, pues menciona explicitamente los sucesos que llevaron a la caida de Oropesa el 28 de dicho mes y año (BNM, Mss. 18212. Debo la noticia de este documento al profesor Delfin Rodríguez, a quien agradezco la información).

${ }^{5}$ Alvarez de Quindós, J. A., Descripción histórica del Real Bosque y Casa de Aranjuez. Madrid 1804, pág. 386: “Don Fernando Valenzuela, que de la esfera de Hidalgo particular llegó a la cumbre de mayor privanza, y a obtener las gracias y empleos de Marqués de Villasierra, Caballerizo Mayor de la Reyna, Capitán General de la costa de Granada, Grande de España, y primer Ministro: fue nombrado Superintendente de las obras de palacio y Sitios Reales por título de 10 de enero de $1675 \ldots$, y en decreto de 15 de enero de 1677 se mandó recoger, anotar y glosar, y que le cesase esta plaza, igualmente que las otras que habia adquirido... Este empleo era de la mayor confianza, y su encargo el manejo de todos los asuntos de las obras Reales, dando las órdenes para su ejecución, y acordando lo necesario con la Junta de Obras y Bosques". 
a su favor el 14 de junio de $1676^{6}$. Con ello se estrechaban cada vez más los lazos entre el arquitecto y el ministro, que delegó en él «toda la disposición de las obras de Palacio, Galerias, Arco y Cocheras, en que se consumieron cantidades considerables" ${ }^{7}$.

Sin embargo, la suerte de Valenzuela estaba echada y su caída se hacía efectiva apenas seis meses después, llevando el infortunio al nuevo maestro mayor. El 25 de agosto de 1677 se producia un hecho sin precedentes al emitir Carlos II una real Cédula nombrando a Francisco de Herrera Maestro y Trazador Mayor de Obras Reales, revocando así su decisión previa ${ }^{8}$. No hemos localizado una documentación específica sobre las circunstancias en que se produjo el cese de Olmo, aunque parece evidente que estuvo determinado por la caída de su protector y por el malestar que habia despertado la actitud del superintendente entre los miembros de la Junta de Obras y Bosques ${ }^{9}$ : Ambos tribunales mantenian

${ }^{6}$ Tras la muerte del maestro mayor Sebastián de Herrera Barnuevo, el 29 de marzo de 1671. Olmo habia concursado para cubrir la vacante, aunque su propuesta fue desestimada en favor del aparejador segundo Gaspar de la Peña, que recibió título en propiedad el 8 del mes siguiente. La noticia de este nombramiento está confirmada por LLAGUNo (Noticias, op cit., t. IV, pág. 47) y en el expediente personal que tiene abierto Peña en el AGP, C. ${ }^{a} 802 / 6$. En vista del resultado y de que la aparejaduría primera estaba ocupada por Bartolomé Hurtado, Olmo solicitó la plaza inmediata, vacante por el ascenso de Peña, y obtuvo título en propiedad el 13 de abril (AGP, Expediente Personal de Olmo, C. ${ }^{a}$ 576/14. Contiene su nombramiento como Aparejador Segundo de Obras Reales en 1671 y como Maestro Mayor en 1676, en ambas ocaciones cubriendo vacantes de Gaspar de la Peña).

${ }^{7}$ Son palabras del Condestable de Castilla y Superintendente de las Obras Reales Don Antonio de Cuellar y Losada, del 16 de febrero de 1711. En este mismo texto expone que "al Duque de Pastrana le sucedió el de Alburquerque, que se excusó de servir la superintendencia y introdujo en ella a Don Fernando Valenzuela, siendo muy reparable que 10 primero que este hizo fue suspender los oficiales Reales Veedor, Contador y Pagador y nombró por depositario de los caudales a Esteban de Casas, Portero de la Secretaría del Despacho..." (AGP, Felipe V, leg. ${ }^{\circ} 460$ ).

El duque de Maura nos proporciona suficientes datos sobre la vinculación que existío entre Valenzuela y Olmo, al referirnos, entre otras cosas, lo siguiente: "Quiso" Don Juan entrar en Madrid después de deshauciado, puesto que pidió audiencia de despedida, pero no "osó" aventurarse en sus calles por su sola cuenta y riesgo porque el aparejador José del Olmo, "brazo derecho de Valenzuela", apostó en lugares estratégicos sus bien armadas cuadrillas de trabajadores...". En otro momento nos cuenta que el valido "hizo seña a don José del Olmo para que patrullasen nuevamente las cuadrillas de ganapanes..." (Vida y reinado de Carlos II, ed. de Madrid, 1990, págs. 169 y 187, respectivamente).

${ }^{8}$ AGP. Libro 16 de Reales Cédulas, fols. 69-70.

${ }^{9}$ La difícil situación en la que quedaba Olmo con la caída de su protector se vio agravada por las acusaciones que se vertieron contra él desde altas instancias, en relación con la ruina del puente de piedra del Pardo, cuya ejecución habia estado a su cargo. Aunque la ruina se produjo en noviembre de 1675, fue en mayo del 77 cuando el Alcayde de este Real Sitio presentó ante la Junta de Obras y Bosques diversas declaraciones de maestros de obras responsabilizando a Olmo del percance. Informado el rey, determinó que se siguieran diligencias judiciales contra su maestro mayor, "en cuya virtud pasó el referido 
desde hacia tiempo un duro enfrentamiento por razón de sus competencias, siendo uno de los principales puntos de fricción la facultad de consultar candidatos al rey para cubrir las vacantes de obras reales, facultad que cada uno se arrogaba para sí. Con ocasión del fallecimiento de Peña el superintendente Valenzuela hizo uso de su pretendido derecho y logró que Carlos II designara a su candidato mediante real decreto, desplazando incluso al aparejador primero o de cantería Bartolomé Hurtado, que podría haber aspirado a la plaza vacante por ascenso regular desde la suya propia.

La Junta no pudo aprobar este proceder, pero terminó por acatar la voluntad del monarca y por reconocer la titularidad del nuevo maestro mayor. Los verdaderos problemas vinieron por la sustitución de Valenzuela en la superintendencia, por la firme oposición que se había granjeado entre los nobles y por el nuevo valimento de don Juan José de Austria, que, con el apoyo de los Grandes, consiguió por las armas el poder político de la Corte y la destitución del anterior privado, en $1677^{10}$.

Su sustituto en la superintendencia, Don Iñigo Melchor Fernández de Velasco, condestable de Castilla, restituyó los oficios de Veedor y Contador, y Pagador de Obras Reales. A instancias del nuevo valido se impugnó el nombramiento de Olmo y se inició la tramitación de una nueva consulta para proveer la vacante de Peña, aprovechando la circunstancia de que el actual maestro mayor no había sacado todavia el título correspondiente a su nombramiento. En esta ocasión, la Junta apoyó a Olmo y consultó ante el rey su nombramiento definitivo, por entender que la designación estaba ya formalizada y que no se podía invalidar el de-

(D. Pedro Cervantes, Alcalde Juez de Bosques) a proceder contra él y le puso preso en la Carcel Real de esta Corte, embargándole sus bienes y estando en prisión por esta causa con segunda orden de su Magd. de 2 de agosto de 1977". Pocos días después, se escrituró un acuerdo que obligaba a Olmo a rehacer el puente a su costa, actuando como fiadores su mujer y su hermano. Con ello quedaba libre de la cárcel, aunque no de problemas, pues entre tanto, se había producido su cese como maestro mayor y el nombramiento de Herrera. Al menos, el desenlace del asunto del puente del Pardo no resultó tan gravoso como podía esperarse. Está referido en AGS, Casa y Sitios Reales, leg. ${ }^{\circ} 376$, docs. 54-56. Informe de D. Francisco de Castro al Secretario de la Junta de Obras y Bosques, con fecha 25 de noviembre de 1968. También mencionó el encarcelamiento de Oimo el duque de Maura, en la biografía del reinado del último Austria, y, posteriormente, TOVAR hizo algunas puntualizaciones, op. cit., 1975, págs. 232.

10 Sobre la caida de Valenzuela y el afianzamiento de Don Juan José puede consultarse Elliot, J. H., La España Imperial (1469-1716), ed. de Madrid 1986, págs. 389-404. El ascenso de aquel y su relación con la reina madre, durante la minoria de edad de Carlos II, fue detallado por el Duque de MaURA, op. cit., ed. 1990, págs. 120-219. También incidió en este tema el Marqués de Lozoya, en su Historia de España, ed. de Barcelona, 1979, t. VIII, págs. 1746 y ss. 
creto real emitido en 1676; el nuevo superintendente, en cambio, desatendió esta circunstancia y, haciendo uso de unas prerrogativas que disputaba con la Junta, consultó ante el monarca a Francisco de Herrera para cubrir el empleo, considerado vacante, logrando que Carlos II expidiera una real cédula a favor de su candidato el 25 de agosto de $1677^{11}$.

11 Hemos reconstruido este controvertido proceso a partir de los siguientes documentos fragmentarios que se conservan en el AGP: En el legajo 294 de la sección «Felipe $V$ » se guarda un memorial de Olmo pretendiendo la vacante de Francisco de Herrera, en 1685. En él explica que "por muerte de Don Sebastián de Herrera fue consultado con Gaspar de la Peña en la plaza de Maestro Mayor de las Reales Obras de V. M. y V. M. fue servido de dar la plaza a Gaspar de la Peña y al suplicante la de aparejador que dicho Peña tenía, y por muerte de este, fue consultado el suplicante en dicha plaza de maestro mayor, y $V$. $M$. fue servido de hacerle merced de ella, de que pagó la media annata... $Y$ habiendo venido su A. a esta corte se mandó a la Junta... consultase dicha plaza... y la consulta que hizo fue diciendo que en justicia no debía V. M. pasar a quitarla al suplicante que era maestro mayor que asi constaba a la Junta por Decreto de V. M... y no obstante... se mandó a Mayordomo Mayor (Iñigo Melchor Fernández de Velasco, Superintendente de Obras Reales y Condestable de Castilla) consultase, y se pasó a proveerla en don Francisco de Herrera, de que se ha seguido al suplicante gran perjuicio a su crédito...". En el expediente persona del Olmo se conservan también, entre otros documentos, la cédula de su nombramiento como aparejador de obras reales en sustitución de Peña, el 13 de abril de 1671, y la que le habilitó como Maestro Mayor a la muerte de éste, el 14 de junio de 1676 (C. ${ }^{a}$ 576/14). La noticia de la restitución de los oficios de obras reales suprimidos por Valenzuela está contenida en el legajo citado de “Felipe $V$ ", núm. 460 (informe de 16 de enero de 1708) donde también se nos informa de las pretensiones del nuevo superintendente Fernández de Velasco, sobre corresponder privativamente a este oficio la consulta de los empleos vacantes en obras reales: «... volvió a rehabilitar a don Gaspar de Legasa Veedor y Contador y a don Melchor de Arce Pagador, porque hasta entonces no debió la Junta de tener ocasión oportuna para sacar la cara por los oficiales Reales. $Y$ continuando mi tio (el Condestable) consultó la Maestría Mayor (se refiere a la de Francisco Herrera, en 1677) y todos los demás empleos de las Obras, no sin oposición de la Junta...". Sobre este mismo asunto interesan las palabras reivindicativas del propio Superintendente Velasco en 1677 cuando, con ocasión de proveerse la vacante de segundo aparejador, expuso ante el rey lo siguiente: "Habiendo entendido que la Junta de Obras y Bosques ha consultado a V. M. la plaza de Maestro Mayor de las Obras de Palacio que servía José del Olmo. He debido representar a V. M. que esta plaza toca el consultarla al superintendente de las Reales Obras, como lo hizo el Marqués de Malpica, que por no haber en aquel tiempo Mayordomo Mayor y estar a su cargo la superintendencia, a consulta suya nombró $\mathrm{S}$. M... a don Sebastián de Herrera (el Marqués detentó el cargo entre 1643 y 1669. La vacante aludida se proveyó en enero de 1662, tras la muerte de José de Villareal, según nos informa Azcárate en su estudio citado, 1962, pág. 533, ratificando las noticias ofrecidas por Llaguno, t. IV, págs. 54 y 59); “el Duque de Pastrana, Mayordomo Mayor de la Reyna... que gobernaba la Real Casa de V. M. y estaba también a su cargo la superintendencia consultó la vacante de don Sebastián y se nombró a Gaspar de la Peña y por su muerte Don Fernando de Valenzuela como superintendente consultó esta plaza y se nombró a José del Olmo y no sólo han consultado las vacantes de Maestro Mayor sino las de Aparejador, Sobrestante y tenedor de Materiales que se ofrecieron en el tiempo de cada uno... Hallándome mayordomo mayor y habiendo puesto $V$. M. a mi cargo la superintendencia de las obras Reales por estas razones me toca consultar la plaza de Maestro mayor y a la Junta de Obras y Bosques (...) mandar despachar por aquella secretaría el título en cabeza de la persona que $V$. $M$. nombra y para que yo pueda pasar a consultar esta plaza esperaré la orden de 
Las consecuencias no terminaron aqui para José del Olmo que, desposeído de su empleo y dañado en su crédito profesional, debió pretender que se le restituyera el cargo de aparejador segundo de obras reales, que detentaba en 1676, y empezó a desempeñarlo en tanto se atendía su solicitud, aunque tampoco por mucho tiempo. En 1678, quizá todavía como consecuencia de los hechos pasados, se consultó esta plaza para proceder a emitir título de propiedad, con todas las formalidades precisas, en cabeza del pretendiente que se considerara más idóneo. También en esta ocasión la Junta debió defender ante el rey la candidatura de Olmo, pero la presión del Superintendente hizo que se desestimara. El mismo Carlos II solicitó de su ministro la proposición de candidatos $y$, en virtud de este parecer, nombró a José Gasén, mediante cédula de 24 de agosto de $1679^{12}$.

La completa rehabilitación de Olmo no se produciria hasta después del fallecimiento de Francisco de Herrera (junio de 1685), cuando obtuvo la Maestría Mayor de Obras Reales tras otro largo proceso que le enfren-

V. M.". Este informe está fechado en julio de 1677, cuando se habia impugnado ya la plaza de Olmo, a consecuencia de los avatares políticos comentados (Exp. personal de Lucas Blanco, $C^{a}$ 126/30). A tenor de cómo se desarrollaron los hechos, podemos concluir que el rey atendió los requerimientos del superintendente en detrimento de la Junta; que le ordenó la propuesta de candidatos, y que, finalmente, nombró a Herrera. La real cédula de su nombramiento se encuentra también en el AGP, loc. cit. Por último, cuando en 1687 se restituyó a Olmo en la maestria mayor, el rey hizo constar en la cédula de nombramiento lo siguiente: “Por cuanto habiendo hecho merced a José del Olmo en catorce de junio del año pasado de 1976 del oficio de Maestro Mayor de las Obras de Alcazar de esta Villa de Madrid y Casas Reales de su contorno que vacó por muerte de Gaspar de la Peña, de que no sacó título para servirle; tuve por bien de nombrar a don Francisco de Herrera para que lo ejerciese. $Y$ habiendo fallecido estándolo haciendo, he resuelto volver a elegir al dicho José del Olmo en atención a sus servicios...". (Libro 17 de Cédulas Reales, fols. 51-52).

12 "Por cuanto he resuelto que José del Olmo cese en la plaza de Aparejador Segundo, de las Obras de Carpinteria del dicho mi Alcazar que ejercia y teniendo consideración a la suficiencia, partes e inteligencia de José Gasén, he tenido por bien de elegirle y nombrarle (...) para que siva el referido oficio de Aparejador de las dichas mis reales Obras, según y en la forma que lo hizo José del Olmo..." (AGP, Libro 16 de Cédulas Reales, fol. 177). Sobre este particular nos informa también el Condestable Cuellar en 1708, al referir que cen consulta de 23 de febrero de 1678 (...) con motivo de haber la Junta consultado una plaza de Segundo Aparejador representó [el superitendente] informando de las razones por que tocaba al superintendente consultar estos empleos ly después de ciertas diligencias|... S.M. respondió... cesase José del Olmo en el oficio de aparejador y propusiese el Condestable para la propiedad de este oficio los sujetos que tuviese por a propósito como lo ejecutó en consulta de 26 de septiembre del mismo año...y S.M. nombró a José Gasén, con que no se puede decir que no fue con pleno conocimiento y exámen de a quien pertenece la facultad de consultar los empleos de las Obras..." (AGP, Felipe V, leg. 460 , doc. cit., y también un informe del Condestable y Superintendente al Veedor de Obras Reales, con fecha 30 de junio de 1707). La aparición de otros documentos puede arrojar nueva luz sobre este asunto, que no aparece reflejado en el expediente personal de José del Olmo en el AGP. 
tó a un círculo muy definido de artistas madrileños: el de los pintoresarquitectos, como su propio antecesor, contra los que arremetió en un documento público que no hemos localizado, pero del que podemos conocer su contenido en virtud de las noticias que proporciona un memorial de José Jiménez Donoso, otro de los pretendientes a la vacante.

Para cubrir el primer empleo de Obras Reales se recurrió a uno de los procedimientos habituales en la época, que consistía en convocar una oposición abierta para que los candidatos demostraran sus facultades ante un tribunal, diputado para el caso por la Junta de Obras y Bosques. Nuevamente contamos con documentos parciales para reconstruir el proceso, pero podemos deducir de ellos que la posibilidad de una oposición fue acogida desigualmente por los pretendientes, según la situación de cada cual. Que sepamos fueron cuatro los que solicitaron el empleo: Pedro de Ávila Cenicientos, Melchor de Bueras, José Jiménez Donoso y el propio José del Olmo. Los memoriales de cada uno de ellos nos informan de diversos aspectos del proceso: Cenicientos explica que se concedió a los concursantes un plazo de veinte dias para realizar las pruebas exigidas, que consistieron en trazar "seis modelos de cortes de cantería de los más selectos = Como es un cielo raso, un capialzado, un arco a dintel por esquina, un arco de viaje contraviaje, un arco de bajada de escalera y una vuelta por tranquil...". En su deseo de ganar méritos para la plaza, se ofrece además a realizar otros muchos cortes de cantería "más exquisitos" $y$, en prueba de voluntad, presenta ante el tribunal la planta y el alzado de una custodia que acababa de ejecutar para la Merced (?), comprometiéndose, si fuera preciso, a «hacerla de cortes de cantería, reduciéndola a la pequeñez de un modelo, para dar a entender que si el artífice arquitecto tiene erudición, hará las obras de todos los géneros que se le sea pedido, pues en lo universal de la arquitectura sólo muda especie la materia, que la formación y los preceptos todos son unos...» ${ }^{13}$. Dávila no alega como mérito el desempeño de ningún cargo oficial en las obras reales o municipales y sólo se titula "maestro en arquitectura", razones por las que debía defender que la plaza se proveyera mediante oposición abierta y no mediante concurso de méritos o mediante simple alegación del desempeño de un empleo inferior a la maestría mayor para acceder a ella por ascenso regular.

Un caso parecido lo constituye el de Melchor de Bueras, que en un extenso memorial detalla ampliamente su formación al lado de su padre, en tierras de Castilla la Vieja, asi como las numerosas obras que contaba en su haber, insistiendo siempre en su peripecia para los cortes de can-

${ }^{13}$ AGP, Felipe V, leg. 294. 
teria y en la solidez y firmeza de sus obras, es decir, en cuestiones técnicas que, por encima de otras especulativas, se consideran ahora imprescindibles para servir un empleo como este ${ }^{14}$.

José del Olmo, por su parte, recordaba las circunstancias que habian llevado a su descrédito en 1677 y reclamaba la maestría vacante como satisfacción del daño recibido ${ }^{15}$. Es fácil suponer que no le agradaría la idea de que se concursara públicamente la plaza, por miedo a volver a perderla definitivamente. En 1685 habia alcanzado la madurez profesional y habia vuelto a gozar de prestigio entre sus colegas por la consecución de otros cargos relevantes, como la propia maestría mayor del ayuntamiento. Faltaba sólo que la corona le redimiera del perjuicio causado años atrás y que demostrara su confianza en él restituyéndole al empleo vacante; por ello no dudó en defender vehementemente la licitud de su nombramiento, en un escrito que dio a la imprenta cuando supo de la intención de convocar una oposición abierta para resolver la plaza. Según se deduce de las noticias que proporciona José Jiménez Donoso, Olmo criticó duramente la cualificación de Francisco de Herrera para el ejercicio de la arquitectura; desestimó la oposición como procedimiento adecuado para cubrir la vacante y desacreditó la candidatura de quienes no tuvieran un conocimiento práctico demostrable en el arte de la construcción, particularmente de los profesores de la pintura, a quienes dedicó las palabras más ásperas.

La reacción de Donoso no se hizo esperar, tanto por lo que le atañia como maestro piritor con experiencia reconocida en obras de arquitectura, como por los lazos que le habian ligado al vilipendiado Francisco de Herrera. En realidad, la actitud de ambos no era producto sólo de su interés personal por la consecución de un empleo, sino que se enmarcaba, además, en el enfrentamiento que mantenían desde hacia años los arquitectos puros con los provenientes del mundo de la cultura y la pintura, es decir, los arquitectos artistas ${ }^{16}$. Era este un debate viejo desfa-

14 Por la información que brinda sobra la andadura profesional de este maestro, reproducimos el texto de su memorial en el apéndice documental, doc. 1.

${ }^{15}$ OLmo se titula "Ayuda de la Furriela (sic) de V.M., Alcaide de las Carceles secretas del Santo oficio y Maestro Mayor de la Villa de Madrid". El contenido de este memorial ha sido comentado más arriba, al tratar del proceso en el que se revocó su nombramiento de maestro mayor de obras reales (Cfr. nota 11).

${ }^{16}$ René Taylor abordó el estudio de este debate a partir del enfrentamiento surgido entre Gómez de Mora y Juan Bautista Crescencio, señalando entonces la diversidad de criterios que imperaban en España e Italia a la hora de conceptuar la arquitectura y establecer sus relaciones con las otras artes liberales. Al personalizar las posturas contrarias que se mantuvieron en nuestro país a este respecto señaló que "en la nueva generación de arquitectos figuraron personalidades tan destacadas como Velázquez, Zurbarán, Pedro 
sado que se apoyaba en la distinta valoración que se hacía de cada una de las dos fases sustanciales del arte edificatorio: la proyectación y la ejecución, la especulativa y la práctica.

La mayor parte de los maestros de obras activos en Madrid en este momento provenían de un entorno laboral artesanal y su formación se había llevado a cabo en el desempeño directo de la cantería y la albañileria, "a pie de obra"; con el tiempo, y paralelamente al ejercicio profesional, habian ido consolidando sus conocimientos teóricos con el estudio de los principales tratados de arquitectura, que utilizaron muchas veces como simples repertorios formales, sin una actitud critica que cristalizara en la formulación de planteamientos propios originales. La mejor arma que poseian para defender sus prerrogativas frente a la intromisión de profesionales de otras áreas artísticas eran sus conocimientos técnicos y la práctica continuada de la construcción de todas sus fases, desde ei ajuste de la obra y su planteamiento hasta la ejecución misma, responsabilizándose también legalmente de los resultados.

Desde que se habia hecho efectivo el cambio de estilo que hizo triunfar el barroco en Madrid, a mediados del siglo XVII, se había consolidado como práctica frecuente la contratación de oficiales procedentes de la pintura y la escultura para obras de arquitectura, sin duda porque su familiarización con los recursos técnicos y ornamentales propios de aquellas dos artes plásticas, así como sus conocimientos teóricos, les permitían tener una visión de la ciencia constructiva distinta a la que poseían los maestros de obras; más cercana a la fastuosidad, a la sugestión y a la pluralidad de matices e interpretaciones que caracterizaban el nuevo gusto y más cara, por tanto, a los promotores de las obras.

En el caso de los escultores la supuesta intromisión era más difícil de establecer por la estrecha relación, a veces identificación, que existía entre arquitectura y escultura cuando ésta comprendia la traza y ejecución de grandes máquinas de piedra o madera, con problemas técnicos

\footnotetext{
de la Torre, Carbonel, Alonso Cano, Juan de Lobera, los jesuítas Francisco Bautista y Francisco Diaz del Ribero, Sebastián de Herrera Barnuevo. Francisco Herrera el Mozo. Juan Rizi, Juan Caramuel, Teodoro Ardemans y los Churrigueras. A estos y a su influencia se debió el que, no obstante la penuria prevaleciente, la arquitectura española evolucionara en la dirección de formas más variadas y del pródigo empleo de efectos de luz, plasticidad y esplendor... Ni siquiera el propio Fray Lorenzo logró escapar del influjo de las nuevas corrientes..." ( "Juan Bautista Crescencio y la arquitectura cortesana española (1617-1635)", Boletin de la Real Academia de Bellas Artes de San Fernando, XXXVIII, 1979, págs. 61126). Algún tiempo después A. R. G. de Ceballos retomó este asunto en un interesante estudio sobre "L'architecture baroque espagnole vue à travers le débat entre peintres et architectes", que contextualiza el problema en términos más amplios y más aprovechabies (Revue de l'Art, 1985, págs. 41-55).
} 
de planteamiento semejantes a los de las fábricas arquitectónicas. Ello no impidió, de todas formas, que su participación en tales empresas fuera criticada también por los maestros de obras. Por su parte, los pintores presentaban un caso más claro de flagrante intromisión en un oficio ajeno, sobre todo en un contexto profesional endógeno, todavia imbuido de un fuerte sentido gremial. Esto podia parecer a priori, pero la realidad era más compleja. La mayor parte de estos artistas, encabezados por Velázquez, poseyeron una formación especulativa muy sólida y unos conocimientos técnicos de matemáticas, geometria, perspectiva y otras ciencias afines que bien podian aplicarse a la práctica constructiva; su ejercicio de la pintura les había puesto en contacto con la arquitectura y habian llegado a identificarse con ella en las ocasiones, cada vez más frecuentes, en que tenian que fingirla con sus pinceles, según el estilo imperante. Dada la entidad del arte que practicaban, tuvieron además la ocasión de conocer de primera mano obras de producción italiana llegadas a España y pudieron, también por esta vía, contactar directamente con algunos de sus autores, pues, desde la afluencia de pintores italianos a Madrid para participar en la decoración de El Escorial, se había establecido un movimiento que no tenía paralelo en la arquitectura. Del mismo modo, durante el período que nos interesa, fue mayor la presencia en Italia de pintores españoles que de arquitectos, con casos tan significativos como los de Francisco de Herrera "el Mozo" o el propio Donoso. Alli había saboreado la hermandad de las Artes y habian disfrutado de un ambiente en el que el debate planteado en la Corte no tenia ya lugar. No está de más que recordemos otra vez la trascendencia que tuvo para la renovación estilística del siglo XVII la presencia de Colonna y Mitelli en Madrid y la decisiva influencia que ejercieron los viajes de Velázquez a Italia para abrir su espiritu a una nueva sensibilidad y, desde luego, para posibilitar que se instituyera en uno de los introductores del barroco en la arquitectura, como señaló Bonet Correa ${ }^{17}$.

Después del intento protagonizado por Velázquez de conjugar el ejercicio de las aries mayores a la manera italiana, se sucederían los ejemplos y, lo que en principio pudo tomarse como una enojosa intromisión ocasional, se consolidó como firme opción alternativa de la mano de figuras como Alonso Cano o su discipulo Sebastián Herrera Barnuevo que, al acceder a la Maestría Mayor de Obras Reales en 1662, contribuyó sin duda a compensar la balanza y allanó el camino a otros artistas de su misma línea, sin que la abierta oposición de los sectores más

17 Bonet Correa, A., "Velázquez, arquitecto y decorador", Archivo Español de Arte, XXXIII, 1960, págs. 248-249. 
tradicionales pudiera hacer nada al respecto, pero sin que debamos pensar, por ello, que durante el reinado de Carlos II se alcanzó un equilibrio de fuerzas favorable a la opción renovadora. De hecho, la coexistencia de estas actitudes encontradas en materia edificatoria siguió generando disensiones en el ámbito de las obras de iniciativa real e interesó también a las de promoción particular, aunque en aquellas alcanzó ahora una significación mayor por lo que implicaba de mantenimiento de unas prerrogativas sociales y profesionales que nadie quería perder, en especial quienes se habian visto favorecidos por ellas durante más tiempo, es decir, aquellos sujetos con un perfil laboral y una formación práctica y especulativa unívocamente encaminada al ejercicio profesional de la arquitectura ${ }^{18}$.

El enfrentamiento entre Jiménez Donoso y José del Olmo, con ocasión de cubrir la vacante de la Maestría Mayor de Obras Reales, es uno de los más significativos y casi podríamos decir que prototípico. Aquel encarna, sin duda, el modelo descrito de artista procedente del mundo de la pintura que completa su formación en Roma, donde tuvo ocasión de conocer directamente los casos que ejemplarizaban la idea del artista universal expuesta por Alberti y consagrada después del Renacimiento. Durante su estancia italiana (que, según las noticias de Palomino, se prolongó por espacio de siete años, desde 1646 hasta 1653, aproximadamente) frecuentó las academias romanas y consiguió «salir gran pintor, perspectivo excelente, y consumado arquitecto" " ${ }^{19}$. Después, a su regreso a España, se instaló en la Corte y, solo o en compañia de Coello, desarrolló los conocimientos adquiridos, produciendo obras con un acusado sentido decorativo y una plasticidad renovada, tanto cuando fingía perspectivas como cuando realizaba tareas de arquitecto ${ }^{20}$.

${ }^{18}$ En el trabajo arriba citado ("L’architecture...", 1985, págs. 47 y siguientes), Ceballos repasa algunos casos significativos a que dio lugar este debate y analiza las posturas que mantuvieron al respecto Juan de Herrera, Gómez de Mora, Fray Lorenzo de San Nicolás o Juan de Torija, en oposición a las representadas por Cano. Herrera Barnuevo, Herrera uel Mozo". Francisco Rizi o Jiménez Donoso, de quien no se conocia hasta ahora el texto que presentamos.

19 Palomino, op. cit., pág. 297.

${ }^{20}$ Con respecto al papel desempeñado por Donoso en la renovación artística consolidada en Madrid durante el desgraciado reinado de Carlos II, Bonet (Iglesias madrileñas del siglo xVII, Madrid, 1961 (1984), pág. 41) afirma "que su frondosa personalidad de pintorarquitecto le convierten en el artista-símbolo del momento en que se prepara la brillante eclosión barroca de José Benito Churriguera y sus discípulos. El tan vituperado Donoso,..., en realidad no fue más que un renovador a la moda de lo ornamental, un artista que a las estructuras simples y tradicionales de la arquitectura española añadió el gusto por una decoración de origen italiano empleado de manera más profusa y difusa. Al igual que Francisco de Herrera el Mozo, Francisco Rizi o Claudio Coello, Ximénez Donoso no hizo más que continuar el tipo de decoración pictórica al fresco iniciada por los italianos Colonna 
Olmo representaba el caso contrario. Su vida estuvo siempre ligada al ejercicio profesional de la arquitectura y circunscrita a un entorno laboral muy cerrado; no viajó a Italia ni se le conocen estudios académicos $y$, si hacemos caso al inventario de los libros que poseía en el momento de su muerte, tendriamos que concluir que sus conocimientos teóricos sobre la materia fueron escasos. Es dificil creer que no poseyera ninguno de los tratados italianos al uso, algunos de los cuales, como los de Vitruvio, Alberti, Palladio, Serlio o Vignola, por citar los más elementales, se habian popularizado incluso entre los maestros de obras y su adquisición no resultaba entonces problemática, ni que tampoco contara con los escritos de autores españoles sobre arquitectura, ingeniería o fortificación, mucho más asequibles todavia, ni siquiera con los repertorios prácticos de Fray Lorenzo o Torija, tan difundidos. Sin embargo, lo cierto es que en su testamentaría no se inventariaron ni estos ni ningún otro sobre asuntos competentes a su profesión, pues, si bien se contabilizaban casi ochocientos libros, 750 correspondian al «auto general que se celebró en esta Corte el año pasado de seiscientos ochenta", cuyo montaje y relación escrita corrieron de su cuenta, y el resto eran obras de carácter literario, filosófico o religioso ${ }^{21}$.

Concluir, a tenor de estas noticias, que José del Olmo carecia de la más imprescindible formación teórica, que sus maniobras prácticas en materia constructiva no tenian un fundamento especulativo o que apenas mostró inclinación por lecturas específicas a su trato laboral sería, no obstante, una conclusión arbitraria y aventurada, contradicha por sus mismas obras, por su andadura social y profesional y por el más que correcto tono literario con que narró el Auto de Fe mencionado más arriba. Si es cierto que no gozó de formación académica, también lo es que la circunstancia no era rara en la época, sobre todo en Madrid, donde entonces sólo se podian seguir estudios normalizados de matemáticas y

\footnotetext{
y Mitelli...". A falta de otros estudios biográficos más precisos sobre este desconocido artista, pueden consultarse las noticias que proporcionaron en su día PALOMINO (op. cit.), págs. 296-299), Cean Bermúdez, (op. cit., t. VI, págs. 8-13); Llaguno (op. cit.. t. IV, págs. 79-80) y, más recientemente, KubleR (Arquitectura de los siglos xVII y xvill. Madrid 1957, págs. 104-108) y Angulo, D., (Pintura del siglo XVII. Madrid 1958, págs. 317-318), este último por lo que atañe a su faceta como pintor.

${ }_{21}$ AHIPM, P. 13846, fols. 305-306. De hecho, sólo se inventariaron a su muerte 31 libros, entendiendo como tales los que pertenecían a un mismo autor y asunto, al margen de los vólumenes o "cuerpos" que tuvieran. El primero de ellos fueron los 750 ejemplares de la relación del Auto de $\mathrm{Fe}$, que todavía conservaba el autor. Los titulos incluidos en el inventario corresponden a la Madre Agreda, Santa Teresa, Fray Luis de Granada, Villegas, Palafox, Virgilio, Kempis, el Padre Seneri, Belarmino, Boscán, Garcilaso, Séneca, Herrera. Jacinto Polo, Séneca, Quevedo, Cervantes, Calderón, el Padre Mariana, y otros varios de carácter similar.
} 
otras ciencias afines en el Colegio Imperial. Olmo pudo satisfacer sus necesidades intelectuales de forma autodidacta, como tantos otros, entre ellos el propio Francisco de Herrera que, al decir de Palomino, "no habia estudiado" y ello no le obstó para convertirse en un señalado pintor y en un "grandísimo arquitecto". Además, José estaba emparentado con los Peña y los Torija en distintos grados y él mismo formaba parte de un clan de arquitectos y maestros de obras, de manera que si no gozó de una librería propia - extremo difícil de creer- bien podría haberse beneficiado de las de sus familiares o, en razón de sus empleos, de la que el rey tenía puesta al servicio de sus oficiales de Obras Reales.

En fin, y para no alargarnos en estas consideraciones, debemos concluir que el dato ofrecido en su testamentaria pierde relevancia al lado de otras noticias y queda a la espera de una explicación más satisfactoria y convincente que nos permita comprender en virtud de qué circunstancias no quedaron reflejados en el inventario de sus bienes los libros más interesantes a su formación profesional. Dando por supuesto que gozaba de ella y que sería esmerada, lo que parece innegable es que sería sustancialmente distinta a la que poseyeron los arquitectos provenientes del campo de la pintura, rechazados como colegas, vilipendiados como técnicos y convertidos en eventuales rivales de los artífices cuyo modelo encarnaba ahora José del Olmo.

Si a todo lo expuesto añadimos el recelo que Olmo tuvo que sentir hacia Herrera "el Mozo" cuando le sustituyó en la Maestría Mayor de Obras Reales, la afinidad de este con Donoso y el peligro que habia de suponer ahora su candidatura para cubrir la vacante - habida cuenta del prestigio que tenia en la Corte y del precedente que había sentado Herrera Barnuevo y el propio Francisco de Herrera a este respecto- el entrentamiento entre los dos candidatos se hacía inevitable. Olmo no se anduvo con rodeos y publicó una dura diatriba contra los pintores metidos a arquitectos.

Donoso se defendió de sus acusaciones y críticas como mejor supo y se preparó para afrontar la oposición presentando ante el tribunal «dos cortes y las trazas y monteas de ellos, que es la materia más dificultosa que se ofrece en las fábricas y de lo que deben saber los Maestros Mayores, por ser la cantería de lo que se han fabricado todas las obras más insignes, y Catedrales. $Y$ allí se necesita de entender muy bien los Cortes de cantería, por las dificultades que se ofrecen". Con esta afirmación, Jiménez parecía entrar en un juego contrario a sus intereses y a los de sus adeptos, un juego que podria llegar a perjudicar su postura argumental sobre la legitimación del arquitecto humanista a la manera albertina, del teórico cualificado por sus conocimientos para ejercer cual- 
quiera de las artes liberales y para formular una teoría estética sin la servidumbre del manejo práctico; pero no debemos olvidar que su consideración se dirige a los Maestros Mayores, que el ambiente de las Obras Reales era, por así decirlo, mucho más realista en tales cuestiones y que son palabras pronunciadas por quien acababa de recibir el nombramiento de Maestro Mayor de la Catedral de Toledo, mérito que alegó para optar a la titularidad en ciernes. Es decir, que con su afirmación pretendía únicamente conjurar cualquier recelo sobre su competencia técnica y la de «los suyos».

Sin más preámbulos, pasa luego a refutar el contenido del texto de Olmo en nombre de todos los Profesores de la Pintura, destacando que, gracias a los estudios adquiridos para profesar este Arte, se encontraba capacitado para acudir a la oposición. Proclamó después la hermandad de las tres artes mayores y enumeró por menor los ejemplos más gloriosos de artistas que profesaron a un mismo tiempo y con éxito la pintura o la escultura y la arquitectura. Los nombres de Bramante, Miguel Angel, Rafael, Bernini, Vignola, El Greco, Juan Bautista Monegro, Juanelo Turriano, Durero, Juan de Arfe, Bartolomé Zumbigo, Alonso Cano, Herrera Barnuevo y Herrera "el Mozo" se entremezclan para ratificar sus teorías y para reafirmarle en la idea de que los conocimientos no son materia excluyente, ni que el dominio de disciplinas diversas pudiera perjudicar al individuo en el normal desarrollo de cada una de ellas, sino, por el contrario, enriquecerle en todas. Siguiendo su razonamiento, concluia que "un carpintero que estudie y que esté en la Arquitectura será arquitecto, solamente llevará ventajas el que fuere más dibujante y entendiere los preceptos que tocan a la arquitectura", virtudes que, sin duda, él se jactaba de poseer. Su razonamiento es intachable, aunque seguramente levantaria ampollas en la mentalidad cerrada de muchos maestros de obràs acomodados en los empleos oficiales más por su buen hacer en materia de albañilería y cantería que por su formación teórica o por su capacidad para sintetizar en una traza sus ideas y planteamientos sobre el arte edificatorio y, aunque se puede contestar a este argumento que tales criterios funcionaban solamente para elección de aparejadores y no para cubrir una vacante a la Maestría Mayor, no debemos olvidar que, según las Instrucciones para Obras Reales vigentes, una de las funciones del aparejador primero era sustituir al maestro mayor en sus ausencias y enfermedades y que en varias ocasiones se proveyó el empleo principal por ascenso regular del inmediatamente inferior, e incluso del siguiente, originándose de hecho una situación que podia encaramar a la Maestría Mayor a un sujeto práctico proveniente de las aparejadurías, consolidando con ello unas actitudes endógenas y gremialistas que perjudicaban la renovación estética de las Obras Reales, entorpecian la mo- 
dernización de los criterios selectivos -en detrimento de la formación especulativa - y cerraban el paso a artistas provenientes de otras áreas.

Teniendo en cuenta todos estos factores se explica el interés de unos y otros en defender su postura en un asunto tan delicado y trascendente, así como el énfasis de Donoso al declarar, como colofón a sus palabras previas, que "en cualquier Profesión, si han estudiado los preceptos de la arquitectura, serán arquitectos sin tener manejo ninguno, pues para saber mandar siendo la disposición suya dará la forma de cómo se debe hacer, como se ve en el Ingeniero de Campaña que para fortificar una Plaza o Castillo él da la forma y sin ser manejante se pone en ejecución su planta y alzado... pues siempre la parte teórica ha superado a la parte práctica, unidas ambas a dos será mejor si se hallan en un sujeto...".

El aspirante es también categórico al defender el sistema de oposición para cubrir las vacantes de Obras Reales, al menos la del maestro mayor. Sin duda porque comprendía que era esta la única vía de acceso posible para las personas que no estuvieran vinculadas ya a alguna de las oficialias, como también ocurría en los casos de los otros pretendientes: Cenicientos y Bueras. La oposición era, además, el mejor medio que tenía un pintor para demostrar públicamente unas aptitudes para el ejercicio de la edificatoria que, desde hacía tiempo, les venian siendo negadas por los arquitectos profesionales y por los maestros de obras. En concreto, consideraba que los interesados debian examinarse simultáneamente y en presencia del tribunal, para evitar que alguno pudiera presentar trazas ajenas, e insistía en que primaran los ejercicios técnicos - cortes de cantería, monteas- y los conocimientos de geometría a la hora de decidir las pruebas ${ }^{22}$.

Queda claro, pues, que, ante la eventualidad de que se convocara una oposición para resolver la vacante dejada por "el Mozo", surgieron enseguida dos posturas bien diferenciadas: la protagonizada por Cenicientos, Bueras y Donoso, partidarios de este sistema por la cuenta que les tenía, y la defendida por Olmo, contrario a examinarse, tanto por el peligro que representaba uno de los oponentes, como por el descrédito que indirectamente se infringía a su persona no concediéndole regularmente la plaza, y también porque con su postura reivindicaba el derecho a la titularidad de la Maestría Mayor de Obras Reales para todos los que,

22 Por el interés que tiene este escrito y la escasez de noticias que todavia hay sobre la vida, la obra y el pensamiento de José Jiménez Donoso transcribimos íntegro su texto en el apéndice documental, doc. 2. 
como él, practicaban la arquitectura profesionalmente, previniéndose contra la ingerencia de personas ajenas. Una sola cosa en común tuvieron todos ellos: la decidida defensa de ciertos conocimientos técricos como premisa indispensable para detantar el cargo pretendido. Bien entendido que en los casos de Cenicientos, Bueras y Olmo esta defensa parapetaba una cierta formación laboral con un sustento teórico muy concreto y definido y una experiencia probada, más o menos relevante, en el dominio de la técnica constructiva; mientras que en el de Donoso, por el contrario, escondía el afán de demostrar públicamente su predisposición a valorar este tipo de conocimientos como complemento indispensable a la formación especulativa que debía adornar a todo arquitecto que se preciara de serlo (en realidad, a cualquier artista), formación que, desde luego, él tenía.

Los problemas surgidos retrasaron la resolución de la plaza, que todavia en 1687, dos años después de la muerte de Herrera, seguía vacante, originando una situación difícil de sostener.

Así debió entenderlo Teodoro Ardemans, que elevó al rey un memorial impreso. Según parece, la dilación en la provisión del cargo habia originado comentarios en la capital de la monarquía y había proporcionado a los "extranjeros" un nuevo pretexto para desacreditar los asuntos españoles. En su escrito, Ardemans no se manifestaba a favor de ninguno de los pretendientes, aunque debía de ser pública la polémica desatada entre Donoso y Olmo, y se limitaba a exponer la necesidad ineludible que la Corte tenía de un Maestro Mayor que supervisara el curso de las obras acometidas en Madrid, así templos como edificios civiles, y no sólo los dependientes de la Corona sino todos los que se fabricaran en el perímetro de la Villa, pues, al ser sede y residencia permanente del rey y sus ministros, competía a su primer arquitecto vigilar todas las construcciones, como asunto ligado al ornato y decoro de la Corte. Recordemos, a este respecto, que la maestría mayor municipal tuvo una existencia forzada y una entidad controvertida durante los últimos tiempos, dándose el caso de que fue muchas veces el primer arquitecto real el encargado de supervisar las obras de la Villa y dirimir algunos problemas surgidos en este campo, avalado por la autoridad y el crédito que le había conferido el monarca. $Y$ recordemos también las peculiaridades del caso de Olmo, de quien no sólo se desconoce la fecha de su nombramiento como arquitecto municipal, que podría deberse a una desaparición fortuita, sino que nunca se menciona en otros documentos. En estas fechas ejercía el empleo con la retribución económica y las competencias correspondientes, pero es posible que su acceso a él hubiera estado marcado por la polémica y hubiera despertado el recelo de otros 
colegas ${ }^{23}$. De momento, sólo podemos aventurar conjeturas, pero en el escrito de Ardemans parece defenderse que ambas maestrías - la de Villa y la de Corte - se concibieran como una sola dimanada del rey; sus palabras pedían que se resolviera en una misma persona la pugna entablada tras la muerte de Herrera, pero no en favor, sino en detrimento, de José del Olmo, que ya parecía incorporado al empleo municipal con todos los derechos. En este sentido interpretamos, al menos, las palabras de Teodoro al reivindicar "el dibujo, Geometría, Aritmética, y Perspectiva" como las "facultades que componen un perfecto Arquitecto, y que sin ellas serán efímeras las obras, de que tiene Vuestra Magestad lastimoso exemplar, continuamente en su Real presencia». Teniendo en cuenta el percance del Puente del Pardo, es fácil que la velada acusación fuera dirigida contra Olmo (la ruina de El Pilar de Zaragoza y el descrédito que supuso para la memoria de Francisco de Herrera estaban lejos todavía) y, además, la mención expresa de la perspectiva entre los conocimientos que debian adornar al perfecto arquitecto, hacia referencia a aquellos que personificaban el modelo humanista de arquitecto-artista y dejaba fuera la candidatura de éste ${ }^{24}$.

Tras las obligadas palabras de respeto, Ardemans comenzó su escrito reclamando para Madrid la instalación de una Academía de Matemáticas, tal y como había propuesto Francisco de Herrera durante el desempeño de la Maestría Mayor de Obras Reales. Por fortuna, todavía se conserva el interesante memorial con que Herrera elevó esta petición al monarca, memorial que hubieron de conocer Donoso y Ardemans y cuyo espíritu anima las palabras de éste. El texto merecería un análisis más detallado que el que podemos incluir aquí, pues aborda directamente el debate antes aludido entre arquitectos profesionales y arquitectos artistas, a partir de la distinción entre artes liberales y mecánicas; de la aceptación y defensa de la hermandad de las artes mayores, y de la valoración del Dibujo por encima de los aspectos técnicos y prácticos de las obras, es decir, la valoración del diseño o la proyectación por encima de la ejecución material. Todo eran cuestiones añejas que ya habian sido resueltas en Italia, pero que aquí constituian todavía una discusión abierta, como resultado de la carencia reiterada de una institución específica (una academia, propiamente) donde se impartieran los conocimientos es-

${ }^{23}$ Sobre este partícular véase mi estudio sobre «La Maestría Mayor de Madrid. Origen, evolución y virtual supresión del empleo", incluido en mi Tesis Doctoral Teodoro Ardenams y su entorno en el cambio de siglo (1661-1726). Aspectos de la arquitectura y el urbanismo madrileños de Felipe II a Carlos III. Madrid, Facultad de Geografia e Historia, Universidad Complutense, 1990 , págs. 276-333.

${ }^{24}$ El escrito de Ardenams es como se traslada en el documento tercero del apéndice. 
peculativos que acreditarian al Artista y le diferenciarian del simple intérprete manual, y también por la presión que ejercieron en esta situación ciertos condicionantes sociales y económicos obviados por Herrera. La elección de las matemáticas como principal disciplina no era nueva y se justificada en que constituían el fundamento esencial de todas las Artes, de tal manera "que no puede ser perfecto Artífice en pintura, escultura y arquitectura, en el que no concurrieran las líneas unidas con el dibujo...” ${ }^{25}$.

Ya hemos podido constatar la admiración de Ardemans hacia Herrera, a propósito de su intervención en el proceso constructivo de El Pilar zaragozano ${ }^{26}$. Ahora es sintomático que, en el contexto de la polémica resolución de la Maestría Mayor de Obras Reales, saque a colación un escrito suyo en el que se defendian el carácter liberal de la arquitectura y se reivindicaba la aportación de los pintores y de quienes tuvieran una formación especulativa multidisciplinar de la que carecian ciertos profesionales de la edificatoria. La formación del Arquitecto debía cimentarse en los conocimientos teóricos y en su capacidad para ponerlos en práctica a través de los oficiales de manos, a quienes sólo correspondía seguir sus intrucciones y aplicar su pericia técnica en la ejecución de la obra proyectada.

Aunque el texto de Herrera está mucho más elaborado que el memorial que redactó Donoso para solicitar su vacante, es evidente que existen fuertes similitudes entre ambos y que los anima un mismo espíritu. También Herrera proporcionaba ejemplos notables para demostrar que «los mayores Pintores han sido Arquitectos, porque uniendo las líneas al dibujo han conseguido la mayor perfección". "La razón es clara -dirá más adelante- porque si el que adorna la traza con el dibujo no sabe Arquitectura, la corrompe; y si el que ha hecho la traza no entiende el dibujo, tampoco sabe pedir lo que ha menester y por esta causa sucede el ser las trazas centones mal colocados, experimentándose la im-

${ }^{25}$ El memorial de Herrera se localiza en la BNM, Mss. 10838 , fols. $386 \mathrm{r}-389 \mathrm{v}$. Ya es sabido que esta iniciativa gozaba de un antecedente muy relevante: ia Academia de Matemáticas fundada por Felipe II en 1582, bajo la dirección de Juan de Herrera. Durante el reinado de Carlos II se alzaron otras voces, además de las de Francisco de Herrera y Teodoro Ardemans, para reclamar la instalación de una Academia pública en la Corte, igual a las que existian en otros lugares de Europa. Se conoce, en concreto, la solicitud de diversos artistas españoles instalados en Roma (QuINTANA, A., La arquitectura y los arquitectos en la Real Academia de Bellas Artes de san Fernando (1744-1774). Madrid 1983, pág. 27). En el apéndice documental, núm. 4, reproducimos el largo e interesantisimo contenido del escrito de Herrera, de quien conviene también recordar su relación con la academia sevillana de Murillo (Cfr. Angulo, D., op. cit., 1958, pág. 340).

${ }^{26}$ Cfr. Blasco Esquivias, B., op. cit., 1990, págs. 217-237. 
perfección que obtienen en sí por no concurrir en ellas lo esencial de esta parte". No cabe duda que Donoso conoció las teorias de su colega y compartió con él un interés común por la Arquitectura, así como un firme rechazo de los maestros de obras y de los arquitectos profesionales, que veían dañados sus intereses e interferidas sus prerrogativas laborales por intrusos procedentes de otro área.

Si de la pugna entablada entre Olmo y Donoso para lograr la Maestría Mayor de Obras Reales salía victoriosa la candidatura de aquel se desandaria el camino recorrido por Barnuevo y por Herrera, en detrimento de los arquitectos artistas y de la propia evolución de la Arquitectura que, so pretexto de sinceridad, homogeneidad y sencillez conceptual, quedaría encorsetada en una rigidez formal de la que estos pretendian liberarla, dando rienda suelta a su imaginación y concibiendo renovados proyectos, con un acusado sentido plástico pictórico y un desarrollo ornamental tan extraordinario que llegaba a diluir las líneas estructurales.

¿Qué postura adoptó Ardemans en esta tesitura? A estas alturas creemos que está clara. El texto de su memorial es poco explícito, pero, sin embargo, ofrece claves suficientes de interpretación. Para empezar se presenta como "profesor en el Arte de la Pintura, y Arquitectura", evidenciando, por tanto, una afinidad con Donoso que no compartía en el caso de Olmo. Recordemos además que su andadura profesional, tras el aprendizaje con Pereda, comenzó de la mano de Coello - pintor muy relacionado, a su vez, con la alternativa artistica que lideraba ahora Donoso- y que en los primeros trabajos que se le conocen demostró compartir las inquietudes renovadoras de este grupo sobre todo en el techo de la sacristía de la capilla del Cristo de los Dolores de la V.O.T., obra que realiza en 1686, es decir, en fechas muy próximas a la elevación de su memorial. Ardemans no poseía una acreditación pública suficiente como para sugerir al rey la elección de uno de los pretendientes, pero sí podía, como ciudadano y como profesional implicado indirectamente en el caso, reclamar la agilización de los trámites y exponer veladamente sus preferencias al respecto. De ahí que mencione con admiración la propuesta fallida de Herrera sobre el establecimiento de una Academia pública en la Corte, "en que reconocieran el benemérito de tan grande ejercicio, y los ignorantes aprendiéramos unos, y a otros desengañaria la elección acertada de Vuestra Magestad, y juntos todos, lográramos la gloria de nuestro trabajo, con la noticia que entonces Vuestra Magestad de él tendría". Al hablar de elección acertada se refiere a la del nombramiento del nuevo Maestro Mayor, como explica más abajo. Desde luego, no era la candidatura de Olmo la que defendia Ardemans: no podía serlo después de la declaración pública de este maestro contra los profesores 
de la pintura, de su inhibición $\multimap$ tal vez abierta oposición- ante la propuesta de Herrera, de las críticas que vertió contra él después de su muerte, de su univalente formación profesional y, si creemos a Donoso, de su ignorancia sobre los grandes artistas italianos, que avalaron con su vida y con su obra las pretensiones de estos arquitectos-pintores cortesanos. De nuevo lamentamos no contar con el escrito de Olmo para poder constatar estos extremos, aunque resulta innegable que pertenecia a un ámbito social, cultural y artístico radicalmente distinto al de Herrera o al de Donoso y también muy distante del de Ardemans.

Teodoro Ardemans llegará a representar una actitud conciliadora entre estos dos mundos opuestos. Su carrera en este sentido es singular, pues, aunque inicia su andadura como pintor, simultanea estos conocimientos con el estudio de las matemáticas, la geometría, la perspectiva y otras disciplinas que le cualificaban también para el ejercicio de la arquitectura. Durante los últimos años de aprendizaje de la pintura y los primeros que como maestro examinado (que coinciden con el asunto que estamos tratando) estuvo ligado a la generación de Herrera, Donoso y Coello, artistas que, siguiendo las directrices marcadas durante el reinado de Felipe IV, habian consolidado la renovación estética iniciada entonces y habian encontrado en la edificatoria una nueva forma de expresión plástica, renovándola, a su vez, y propiciando una reciprocidad inusual entre las Artes que practicaban, al modo italiano.

Sin olvidar nunca su condición de pintor, Ardemans terminó por entregarse al ejercicio de la arquitectura. Su formación teórica y la confluencia de una serie de circunstancias que no hacen al caso le permitirian acceder a la Maestría Mayor de las catedrales de Granada y Toledo, asi como a los empleos más importantes de la Villa y de la Corte. Pero esto será con el correr del tiempo. Mientras llega el momento de su consagración profesional, tiene que ajustarse a la realidad laboral de entonces y comenzar a practicar la arquitectura desde abajo, como un simple alarife, en lo que respecta a su relación con el municipio, o como un asistente eventual, por lo que atañe a las Obras Reales. Sin la entidad artística de los pintores que admiraba $y$, desde luego, sin su bagaje profesional ni su crédito, no podía merecer los puestos más relevantes, por lo que hubo de alcanzarlos paulatinamente. No cabe duda que esto le sensibilizaria de manera especial y determinaria su actitud futura ante un problema que ahora todavía vivía desde la óptica del iniciado que se sentía cualificado por enriquecer con sus opiniones y conocimientos el Arte de la Arquitectura. No en vano, al defender ante el monarca la necesidad ineludible de resolver la plaza vacante, insistia en esta valoración del Maestro Mayor como hombre docto en las materias especulativas; un hombre 
que debería supervisar el curso de las Obras Reales, aunque "sin necesidad del uso mecánico de manejar la materia... pues para este efecto lo provee Vuestra Magestad de ayuda de traza, perito también en las mismas facultades, y de Aparejador para cada materia". No eran imprescindibles, por tanto, los manejos técnicos que argumentaba Olmo para conseguir el empleo y sí, en cambio, la formación teórica de Donoso para acreditar a un Maestro Mayor como "Atalaya de todas las obras de la Corte", de quien dependerían nada menos que la seguridad "del Culto Divino, de la Real persona de Vuestra Magestad, de la utilidad pública, del crédito dela Nación Española, ...».

El paso del tiempo y sus propios avatares profesionales desviaron el interés de Ardemans de estos problemas juveniles hacia otros derivados de su contacto cotidiano con la práctica constructiva, ejercida desde la maestría mayor de obras municipales y reales, que empezará a servir en 1702. Sin embargo, nunca se desinhibió de la polémica, ni traicionó su doble naturaleza de pintor y arquitecto. En definitiva, era una sola, la de artista universal al modo italiano, la que defendía. Como otros colegas en los medios oficiales, no pudo sustraerse a la realidad local del momento y se vio condicionado por la necesidad de atender unas obligaciones muy rutinarias, que dejaban poco sitio al desarrollo de la individualidad creadora y sofocaban las mejores iniciativas de cambio y progreso en un marasmo administrativo y ejecutivo dificil de vencer; sin embargo, no desatendió su formación teórica, que siguió alimentando a lo largo de su vida, como bien demuestra la extensa biblioteca que se inventarió al momento de su muerte. Es cierto que desde 1702 -incluso antes- su actividad como pintor fue bastante escasa y de calidad no comparable a la de los maestros que guiaron sus pasos en el periodo de formación, pero no debemos olvidar que en 1704 reclamó y obtuvo del monarca el título de Pintor de Cámara. De esta forma, volvía a producirse una circunstancia que no habia tenido lugar desde la muerte de Sebastián Herrera Barnuevo y se conciliaban definitivamente las posturas que, durante años, habían enfrentado a los arquitectos profesionales con los arquitectos artistas. Entonces el debate estaba ya gastado y no tenía razón de ser, puesto que Ardemans, al contrario que sus predecesores en la pugna, no era un pintor que pretendiera ejercer la arquitectura so pretexto de unos conocimientos teóricos, aprendidos a lo largo de su formación como artista plástico, que le cualificaban también para la ciencia constructiva, sino una persona que se habia formado silmultáneamente para el ejercicio de las dos Artes, aprovechando la circunstancia de que ambas se sustentaban en fundamentos teóricos comunes, que ciertamente exigian luego una aplicación diferenciada. 
Este matiz, y la evidencia probada de que había accedido a las obras municipales y reales tras una larga carrera profesional, le acreditaron a los ojos de los recelosos maestros de obras y de los arquitectos profesionales y le convirtieron en el conciliador de las dos posturas enfrentadas. Con el bagaje cultural que poseía y con la experiencia adquirida a lo largo de los años, pudo llevar a cabo una actividad ciertamente meritoria en el campo de las obras de iniciativa pública. Al frente de ellas se esforzó por mejorar los aspectos más descuidados del urbanismo y la arquitectura de la Villa y de la Corte, sin desatender las muchas obligaciones que le imponian sus cargos, cumpliendo y haciendo cumplir a sus oficiales con las Instrucciones al uso y velando por la continuidad del empleo que ejercía al frente de las Obras Reales, en un momento delicado a causa de los nuevos criterios que trataba de aplicar la dinastía entrante.

Pero volvamos ahora al caso que nos ocupa. El 3 de septiembre de 1687 , dos años después de que se produjera la vacante de la Maestría Mayor, por muerte de Francisco de Herrera, el rey se decidió a proveer la sustitución en José del Olmo, promulgando una real cédula en la que hizo constar brevemente los sucesos acaecidos desde $1676^{27}$. Como en otras ocasiones, volvia a desestimarse en la práctica el sistema de oposición, cerrando el acceso a Obras Reales a quienes no tuvieran alguna vinculación previa con este cuerpo de oficiales, y fomentando, por tanto, la continuidad de unos esquemas de comportamiento endógenos, que dificultaban la renovación cultural de este medio. Con el nombramiento de Olmo, se consolidaban los planteamientos tradicionalmente vigentes en la Corte y se resolvía la pugna entablada a favor de los profesionales. La situación no cambiaría hasta 1702, con la llegada de Ardemans a la Maestria Mayor y la paulatina renovación borbónica: entonces el problema adquirirá nuevos matices, pero este asunto tendremos que abordarlo en otro momento.

${ }^{27}$ AGP, Libro 16 de Cédulas Reales, fols. 51-52: “Por cuanto habiendo hecho merced a José del Olmo en catorce de junio del año pasado de mil seiscientos setenta y seis del oficio de Maestro Mayor de las Obras del Alcázar desta Villa de Madrid y Casas Reales de su contorno, que vacó por muerte de Gaspar de la Peña, de que no sacó título para servirle; tuve por bien de nombrar a don Francisco de Herrera, para que le ejerciese. $Y$ habiendo fallecido estándolo haciendo, he resuelto volver a elegir al dicho José del Olmo en atención a sus servicios para que sirva el dicho oficio...". 

APÉNDICE DOCUMENTAL

\section{Documento 1}

"Melchor de Bueras Maestro Arquitecto.. dice que ha empleado los días de su vida en el ejercicio y práctica de su arte, ideando, trabajando y perfeccionando las obras siguientes: Los principios y escuela que tuvo fue con su Padre, que fue grande Artífice, y asistió en Castilla la Vieja en diferentes obras, que tuvo en las Villas de Aranda, Roa y Peñafiel, y en la Ciudad de Soria, y otras partes de que no hace mención, y en todas se hicieron Iglesias de planta y reparos muy considerables en cuya práctica se halló, y en la ciudad de Soria asistió nueve años, y en ese tiempo hizo de planta la Iglesia de las Monjas Carmelitas descalzas con algunos cortes de arcos de viaje, contraviaje y vueltas de apainel y otros diferentes de medio punto, y a regla, y en la Casa de los Ríos de dicha Ciudad hizo un reparo de mucha consideración en la galería de encima del juego de pelota, que el rempujo de la armadura del tejado le habia echado fuera de su plomo, y macizó tres pies y le apeó desde su planta con cadenas de fortificación, y le demolió y volvió a hacer poniéndoles en la misma forma que estaba cuando se hizo de nuevo, dejándole muy permanente y seguro, y todo esta dicha obra es de canteria. En dicha Ciudad hizo otros muchos reparos de cuidado, y fortificación en la Puente del Rio Duero y plantó con planta arfificial el henchidero de los aguadores, que hizo de nuevo de canteria, el cual entra treinta pies dentro del remanso del Rio, y está hoy permanente y firme, sin otros muchos reparos que hizo en dicha Ciudad de consideración, de que por no ser molesto no hace mención. $Y$ ha veintinueve años que vino a asistir a esta Corte, y recién llegado fue a hacer la iglesia de Valdemoro, y la plantó como hoy está, y de alli fue a Aranjuez y plantó la fuente grande que está a la entrada del Jardín de la Isla de Aranjuez. Vino y hizo la portada de la Iglesia Parroquial de San Martín de esta Corte, y después hizo las Portadillas de la Capilla de la Virgen del Buen Consejo del Colegio Imperial y la obra de la torre del Noviciado de la Compañia de Jesús y hizo la cornisa del cuarto de su Magestad en la Galería que cae al Jardín de la Reina... En Oropesa hizo la obra del Colegio de San Bernardo, de que es Patrón el Conde de Oropesa, que es obra muy considerable y de todo cuidado y Arquitectura, y asistiendo en Oropesa hizo un reparo de mucho cuidado, y fortificación en las aceñas de su Exa que están en el Rio Tajo, que llaman las del Torrico, que se había llevado el Rio el tajamar que divide las Canales de las dos aceñas, y para volverle a hacer cortó el rio, y le plantó de nuevo, y hizo en toda perfección y fortificación que 
está permanente, y otros reparos que hizo en aquel tiempo en Cebolla y otras partes no las dice por no alargarse.

De Oropesa vino a acabar las torres del Colegio Imperial de esta Corte, y tiene hecho en dicho Colegio acabadas dichas torres y la portada principal del dicho Colegio, y el patio, que tienen (sic) comenzado y la escalera principal y otras muchas cosas de que no hace mención. En la casa Profesa plantó la Iglesia toda y hizo las portadas de mármol que están en el transparente que hizo don Francisco de Borja en dicha casa Profesa. Asimismo hizo la portada que está en el Colegio de los Niños Músicos de la Real Capilla, y asimismo el arco del Buen Retiro para la entrada de la Reina Nuestra Señora. Y en la casa del Duque de Osuna hizo la escalera principal, la cual y la del Colegio Imperial, que dice arriba, tienen sus arcos de vuelta de tranquil y vuelta de cordel, que son todos buenos cortes de cantería.

En Alcalá hizo el cuarto del Colegio de la Compañia de Jesús y les dió planta para todo lo que se ha de hacer después para la comodidad de toda la casa y estudios.

En Navalcarnero hizo la barbacana del cementerio de la Iglesia Parroquial, que es obra de fortificación, por estar en un derrumbadero y ser obra de mucho terrapleno, y la hizo con todo cuidado de firmeza y hermosura, y de otras muchas obras y reparos que ha hecho no hace mención, aunque son considerables, por no cansar. Sólo pone por corona el reparo que hizo en el Real Palacio de la Reina Madre Nuestra Señora, con todas las circunstancias que es público. Por todo lo cual y por el crédito que tiene granjeado en la ejecución de dichas obras, las cuales ninguna ha flaqueado ni amenaza flaqueza en la muestra que dan y solidez que tienen; ahora con todo rendimiento pone a los pies de V. Exc $^{a}$ esa planta, corte y alzado que es idea muy singular, sin ejemplar de otra ninguna del género, y es de toda perfección, hermosura y fortificación...» (AGP, Felipe V, leg $^{\circ} 294$ ). Estas noticias completan las ofrecidas por Tovar sobre la actividad profesional de Bueras (op. cit., 1975, págs. 365-373 y "Melchor de Bueras, desconocido arquitecto del siglo XVII', Actas del XXIII Congreso de Historia del Arte. Granada 1977, págs. 564-578).

\section{Documento 2}

«Joseph Donoso Maestro Mayor de la Santa Iglesia de Toledo (por nombramiento de 13 de agosto de 1685) y su Pintor, puesto a los pies de V.S.L., dice: Que tiene concluídos dos cortes y las trazas y monteas 
de ellos, que es la materia más dificultosa que se ofrece en las fábricas, y lo que deben saber los maestros mayores, por ser la cantería de lo que se han fabricado todas las obras más insignes, y Catredales (sic) y alli se necesita de entender muy bien los Cortes de Cantería por las dificultades que se ofrecen.

Digo Señor que a manos de los Profesores de la Pintura ha llegado un memorial que ha dado a V.S.L. José del Olmo, impreso alabando tanto su magisterio y disminuyendo la de los Profesores de la Pintura a que me es preciso responder en nombre de los de mi Profesión que me precio mucho de profesar, que por ella he estudiado para poder salir a esta oposición que hago. $Y$ está poco noticioso en lo que dice porque la Academia en Roma se intitula Academia de Pintura, Escultura y Arquitectura, porque en todas las tres se estudian unos mismos preceptos y esta es causa de haber habido tantos Arquitectos Pintores y Maestros Mayores en Italia y en España y por todo el mundo, pues el que empezó el templo de San Pedro fue Bramante y después le siguió Michael Angel, a quien siguió Rafael de Urbina, todos tres Pintores insignes. $Y$ en lo que trae José del Olmo del cuento de Michael Angel poco noticioso era el que escrió (sic) pues no sabía que Michael Angel fue Pintor pues que pintó el cuadro del Juicio, tan renombrado que Su Magestad tiene uno en Palacio y otros mucho que se ven. $Y$ en mis tiempos estando yo en Roma el Maestro Mayor que habia, que era el caballero Bernino tan nombrado en el mundo, era Escultor y Pintor, y Jacome de Vignola que escribió el libro de preceptos de arquitectura a quien siguen todos era Pintor, como él mismo lo dice en el libro de Prespetiva (sic) que escribió, y los más escritores afamados de Arquitectura fueron Pintores. Y en España en Toledo Dominico Greco, el que hizo la fábrica del Hospital de Afuera tan nombrado y su ayuntamiento no le obstó ser gran Pintor para ser grande Arquitecto. Y Juan Bautista Monegro, el que hizo los Reyes del Escorial no le obstó ser grande escultor para ser grande arquitecto y fabricar en el Alcázar de Toledo el cuarto que mandó hacer el señor Rey Felipe Segundo, escalera y Capilla Real tan nombrada, y Juanelo tan nombrado por el injenio que inventó del agua y tantas fábricas tan grandes como hizo y cinco libros que andan manuscritos no le obstó el no ser manejante para ser grande Arquitecto y Dibujante y Alberto de Urero (sic) tan loado en el mundo por sus obras de Pintura, no le obstó ser Pintor para ser tan grande Geómetra y haber escrito el libro de Geometría, a quien cita el Bachiller Moya y Juan de Arfe en sus obras, ni haber escrito el libro de Simetría y de fortificación y tan grande Arquitecto como fue. Los genios de los hombres unos tiene de valor cuatro y a otros les da Dios de valor ocho y a mi antecesor Don Bartolomé Zumbigo reedificador del Escorial con las ventajas que el mundo sabe, de quien se decia 
que era marmolista y no entendía fortificación y que sus obras se colgaban con grapas, que a no haberle tenido Dios en España se andaba disponiendo el enviar por hombre a Italia para el acierto de dicha obra en que se conoce el grande acierto que tuvo, no le obstó ser marmolista para ser grande arquitecto. $Y$ en Madrid no le obstó a Alonso Cano el ser Gran Pintor para ser Grande Arquitecto y grande escultor. Don Sebastián de Herrera Pintor de Cámara y Maestro Mayor de Su Magestad y escultor grande no le obstó el saber lo uno para estudiar lo otro. Juan de Arfe Platero el que escribió el libro de Geometría y Arquitectura que le tienen todos, fue grande Arquitecto y escultor y no le obstaría el ser Platero para ser maestro mayor $=y$ en Resolución Señor un carpintero que estudie y que esté en la Arquitectura será arquitecto, solamente llevará ventajas el que fuere más dibujante y entendiere los preceptos que tocan a la arquitectura. $Y$ así mejor fuera gastar el tiempo en trazar que en escribir en descrédito de nadie. Don Francisco de Herrera como ya V.S.L. ha visto las trazas del templo de $\mathrm{N}^{a}{ }^{a} \mathrm{~S} .{ }^{a}$ del Pilar cosa tan insigne y tan discreta en su buena elección y vencidas sus dificultades con el acierto que ellas se han dejado ver tan alabadas de todos aquellos que tienen inteligencia en las líneas y dibujo, y por último con los apuntalados que hizo asistiéndolos él se hizo el reparo del Palacio de la Reina Madre; y en cuanto a los del Riego, la avenida le cojió sin tenerlo concluído que fue la causa de Robar lo que le Robó, y esto fue no asistiendo él. Y finalmente Don Francisco de Herrera no destruyó tanto el hacienda Real como otros y era un hombre general, su omisión y descuido no le alaba, que si él hubiera asistido no le hubiera sucedido el llevarse el Pedazo de Presa que se llevó el Rio. Y en cualquiera Profesión si han estudiado los preceptos de la arquitectura serán arquitectos sin tener manejo ninguno, pues para saber mandar siendo la disposición suya dará la forma de cómo se debe hacer, como se ve en el Ingeniero de Campaña que para fortificar una Plaza o Castillo él da la forma y sin ser manejante se pone en ejecución su planta y alzado con sola su asistencia, como lo vemos también en el libro que escribió el capitán Rojas que nos dice y nos enseña como hemos de fundar en pantanos y rios arenosos, a estacar y hacer cadenas de fortificación y presas de molinos con grandísima inteligencia y acierto, y este no era manejante, sino es arquitecto. $Y$ a este tenor muchísimos ejemplares que hay, pues siempre la parte teórica ha superado a la parte práctica unidas ambas a dos será mejor si se hallan en un sujeto. $Y$ hoy dia se les ofrece a los opositores la ocasión más gloriosa que podian desear, que es el salir a la oposición por ser el opositor Pintor adonde podrán lograr la dicha de que luzcan sus grandes ingenios.

Pido y suplico a V.S.L. para en adelante alentar a los que estudian 
no se excuse la oposición que es el camino de criar hombres de habilidad, que para ser la oposición como debe ser se han de juntar los opositores en una parte separada donde tracen juntos delante los unos de los otros, dándose ellos mismos los asuntos los unos a los otros para trazar, y tiempo limitado, para su determinación, y hacer plantas, alzados, cortes, y hacer modelos de cortes de canteria que es la dificultad que se ofrece en las obras magnificas, y hacer monteas y dar la razón de las saltareglas (sic) para su ejecución y en la Geometría medir las figuras o figura corpóreas que se da a cada uno o en la Planimetría, y esto sea sin dar lugar a valerse de habilidad ajena, en que espera el suplicante guardará justicia V.S.L. en que salgan a la oposición y darla al que lo mereciere por ser materia de punto a que no puedo (sic) faltar como lo espera de la grandeza de V.S.L.» (AGP, Felipe V, leg. ${ }^{\circ}$ 294).

\section{Documento 3}

"Señor. Postrado a las generosas plantas de Vuestra Real Magestad, Teodoro Ademanus, professor en el Arte de la Pintura, y Arquitectura, dize, viendo la dilación en la plaza de Maestro Mayor de sus Reales obras de Vuestra Magestad, que han los Estrangeros glosado en desdoro de la Nación Española, à quien, ojalá Vuestra Magestad fuera servido de conceder en su Real Corte publica Academia, como pidió Don Francisco de Herrera, en Memorial que presentó a Vuestra magestad, ò conferencia en este lance, en que reconocieran el benemérito de tan grande exercicio, y los ignorantes aprendiéramos unos, y a otros desengañaria la elección acertada de Vuestra magestad, y todos juntos, lográramos la gloria de nuestro trabajo, con la noticia que entonces $V$. M. de él tendria. Es ya, Señor, necesidad divina, privada de la Real Persona de V. M., y publica de la Corte, y de los Reynos de España la de esta elección, la divina aviva el Católico ardiente celo, que arde incesante en el Real magnánimo corazón de . V. M., en tanto Templo, como continuamente para el Ornato del Culto Divino, se fabrica en su Rea! Corte, para que vistos, medidos, y reconocidos por un tan grande Arquitecto, como será el electo, vayan labrados, conforme a Arte, asegurando su duración, y hermosura a los edificios, y las vidas a los fieles vasallos que los frecuentan: riesgo conocido es este; porque aunque emulen al tiempo su duración los edificios, ultimamente las consume, y arruina. $Y$ así, Señor, estos Reynos necesitan de la mesma elección, para seguridad de la Real persona de V. M., que es el corazón de todos: Es también publica la necesidad, porque siendo el Maestro Mayor Atalaya de todas las obras 
de la Corte, faltando persona pública, docta (como lo han sido los Maestros Mayores, en el dibujo, Geometría, Aritmética, y Perspectiva, facultades que componen un perfecto Arquitecto, y que sin ellas serán efímeras las obras, de que tiene V. M. lastimoso ejemplar, continuamente en su Real presencia) que los reconozca, mida, y registre, es más que natural en ellos el desacierto, de que se originan tantos gastos, y se exponen a tan fatal riesgo tantas vidas; la hermosura y ornato de los ya fabricados, es preciso deteriorarse con el tiempo, si V. M., como lo han hecho todos sus gloriosos progenitores, no tuviera continuamente su Maestro Mayor, para que como Corte pública la remedie, y sin necesidad del uso mecánico de manejar la materia; pues fuera imposible a un hombre solo acudir a tanto género de Fábricas, pues que este efecto lo provee $V$. M. de ayuda de traza, perito también en las mismas facultades, y de Aparejador de cada materia. Los motivos de el Culto Divino, de la Real persona de V. M., de la utilidad pública, del crédito de la Nación Española, y el deseo de saber, de quien deba aprender, me arrastran a los Reales pies de V. $M$., desde donde con el rendimiento, y humildad que debo, suplico acuda con su Real elección al Culto de la Religión Católica, a la seguridad de su Real persona, a la utilidad pública, a darnos Maestro Mayor que nos documente, como lo espero del celo, de la vigilancia, cuidado, y desvelo con que V. M. asiste, mira, y gobierna la Religión, sus Vasallos y sus Reynos» (BNM, VE/ C $\left.C^{a} 64-97 ; 1212-58\right)$. El texto íntegro de este memorial fue dado a conocer por TovaR, V., (Arquitectura madrileña del siglo XVII. Madrid 1983, págs. 703-705, doc. 110).

\section{Documento 4}

“Don Francisco de Herrera, Maestro Mayor de las Obras Reales de V. M., dice, que reconociendo el grave perjuicio que se les sigue a las obras públicas en la falta de comprehensión en las Artes, no distinguiendo las mecánicas de las liberales, ni la práctica de la expeculativa, concurriendo a este sentir el ver que se inclinan los más a los que hablan, que a los que obran, pensión de la poca aplicación, que no hace ojecto (sic) a los Artífices, por cuya razón los Romanos hicieron separación de las Artes liberales, distinguiéndolas de las mecánicas para que no se tuviese por Artífice a el que no tuviese las partes proporcionales a su fin, dando a entender que el Arte, como lo difine Aristóteles, y Platón, es un aviso, y regla efectiva continuada en proporción; y el que la profesa debe juzgar, y saber todas las cosas que le tocan, no en la parte, sino en el todo. 
A la pintura llamó Architas Tarentino ciencia Mathemática, dándola el primer lugar, porque inmediatamente se vale de la Geometría, prespectiva (sic), y octica (sic), que es significación della. La Arquitectura, según Vitruvio, es Arte tan principal, que contine debajo de sí a otras sirvientes, y menores, como son el Cantero, Carpintero, Cerragero, y albañil, y a todas las demás Artes estructorias (sic), cuyos fines sirven de medios al Architecto para conseguir su principal fin.

Por esta razón los mayores Pintores han sido Architectos, porque uniendo las lineas al dibujo han conseguido la mayor perfección. Esto se verifica por las obras grandes de Alberto Durero pintor insigne laureado en Roma, Raphael de Urvino, de quien dice Sebastián Serlio, hizo la planta de San Pedro de Roma (vease si había falta de Architectos en aquel tiempo de otra especie) $Y$ lacome Viñola por quien oy se goviernan los modernos fue pintor, como él lo dice en su prerspectiva. Pedro Perusino (sic), y Brabante (sic), y Michael Angel todos pintores, Architectos y Escultores, que esplicaron estas tres Artes en tres circulos unidos, dando a entender gozan de una misma circunferencia siendo cada una centro de todas.

Distinguense las Artes liberales de las mecánicas en tener más parte de la expeculativa, que de la práctica; y darle más honores, y más crédito a la práctica, es un perjuicio de la República, y en perjuicio manifiesto de la verdad, y en desdoro grande del entendimiento, porque sería dar a entender ser de más estimación hacer una espada que saberla jugar, y herrar un caballo que saberle mandar; dar premio a la pluma por su carácter que no al Secretario por su entendimiento, debiendo ser todo lo contrario, y incurriria en este mismo sentir el que llamase al Albañil Architecto, porque pone mano en las obras.

Explica este sentir el Architecto Militar; pues con solo saber mandar cuatro soldados visoños consigue una fábrica de quien se fia la defensa de la República, y el honor, y crédito de las Armas del Principe: y dado caso que necesite de Albañiles, y otra especie de Artífices para el manejo de su fábrica están a su orden, porque la expeculativa a ellos no les toca el saberla; $y$ así cómo quieren persuadirse a que pueden aspirar a merecer el nombre, y excelencia de Architecto, o de Maestro de obras, como lo pretenden algunos, sin considerar, que se exponen al mismo desaire que mereció un Maestro de Obras, que al tiempo de entrar en casa de Alejandro Grimaldo, Caballero Ginoves, habiéndole preguntado, sí había estudiado a Vitruvio, y reprehendídole de que no le hubiese visto, pues no podía saber, ni aun las reglas de que se debe componer un perfecto Architecto, se satisfizo con una respuesta muy semejante a la que darían algunos de los Maestros, que se hallan hoy en la injusta 
posesión deste renombre con estas palabras: Busque Vmd. un Architecto, que acá los más de los Maestros de obras no sabemos más que cuatro guarismos.

Con justa razón se debe atender al reparo de la causa pública, considerando, que aunque se executen las cosas rectilíneas, o circulares, reducidas al compás en planta $u$ alzado plano, que llaman ignographia, y ortorgraphia (sic), no puede pasar adelante sin la excenographia, que es prespectiva; y si en ella no se valen del dibujo, tampoco pueden conseguir fin perfecto en las cosas irregulares, siendo común sentir de todos los Architectos, que no puede darse este título a el que no tuviere las partes necesarias para poder perficionar la traza, u obra que de su orden se ejecutare, haciendo para ello modelos, o cortes para su inteligencia, porque el que se quedare en solo la planta, u cuatro perpendiculares para su alzado no es bastante para su ejecución, y sólo tendrá entendido, que sabe una porción corta de la Arquitectura, porque ninguna parte es el todo. La razón es clara, porque si el que adorna la traza con el dibujo no sabe Arquitectura, la corrompe; y si el que ha hecho la traza no entiende el dibujo, tampoco sabe pedir lo que ha menester, y por esta causa sucede el ser las más trazas centones mal colocados, experimentándose la imperfección que obtienen en sí por no concurrir en ellas lo esencial desta parte.

Y a este conocimiento práctico perteneció la inteligencia de la fortificación de las obras, porque en rigor no es más que oposición o ángulos, tocando esto inmediatamente a la Geometria, y no a lo material de la forma; y por esta razón, Pitio, uno de los antiguos Architectos fue elegido para la traza del Templo de Minerva, porque siendo gran dibujante, no había puesto las manos en obra alguna, dando a entender en esto, que solo era bueno para una elección tan divina, Artifice, que se había ocupado en comprehender lo que miraba, y no ensuciarse en lo que veia; $y$ publica este sentir Escopinas de Siracusa, que puso pública academia, defendiendo, que no se podía demostrar cientificamente las líneas proporcionales sin el significado del dibujo, porque en su simetría estaba la grandeza de Filósofo, y si ocurrimos al orígen del dibujo, lo publica Teucicedes (sic) en su Geometría, que partiendo en una cantera de mármol una piedra, hallaron la imágen de Sileno esculpida dentro della, de donde se arguye ser fábrica antes del Diluvio; y esto conviene en lo que dice Tesibio, que Alpharat, dos años después del Diluvio le enseñó a Salee el dibujo, el cual no permitió por amigos, y confidentes sino aquellos que debajo de fundamentos geométricos le hablaban; y de aqui se originó la gran significación de las figuras geométricas; y esto tiene gran similitud con la simetría que guarda el dibujo. 
Aquella tan celebrada estatua de la Diosa Minerva, que era toda de marfil de aquel ilustre Escultor Griego Fidias, que se colgó della la perla tan celebrada de Cleopatra, Reyna de Egipto, que Augusto César hizo partir por medio para zarcillos, o arracadas de esta Diosa, que pesaba media onza, apreciada en ducientos sextercios, que valen ducientos y cincuenta mil ducados. Dice Plinio en el octavo libro, que era único milagro de la naturaleza, y por excelencia de su Artífice estaba puesto en la estatua estas palabras: Labróla Fidias, que solo se ocupa en las cosas de los Dioses. Qué diferente es esto de lo que se usa ahora, que se suele echar mano del que solo se ha ocupado en remendar paredes: Por cuya razón los Antiguos hicieron Templo a la honra por ser la basa fundamental de la virtudes, colocando a esta excelencia la exaltación de los buenos Artífices. Y Marcelo fue el primero que votó el Templo de la honra, y virtud, como dice Titolibio (sic) en el 7 libr. de su primera Década; y en este sentir piblicaron los Filósofos, que no había honra en quien despreciaba las virtudes, y no puede haber mayor desconsuelo, que preferir la malicia particular al bien común de que debe hacer particular representación a $\mathrm{V}$. Magestad.

Lustre es de la patria, y honor de la nación en dar glorias, y honores a el que en su facultad es más esclarecido; hajar la habilidad, menospreciar la sabiduría, abandonar las virtudes, disimular con mordacidad el trabajo, del más aplicado, es aborrecer la gloria de su patria, y a sí propio se envilece. De la manera que las familias grandes hacen prendas de las virtudes de sus antepasados; de la misma manera es honor de la patria el singular Artífice, y por esta razón tenian los Antiguos costumbre de guardar los retratos de sus predecesores, y lo continuaban hasta en las honras de sus difuntos, como lo publica Plinio a los treinta y nueve libros de su Historia Natural, y lo afirma Cornelio Nepote en el lib. de los Varones ilustres: la imágen de Catón se llevaba en honras de difuntos: de las mudanzas de los tiempos no me admiro, porque el tiempo es la misma mudanza, y se reconoce en la Era presente: Que si los Antiguos blasonaban de los retratos de sus predecesores como antorcha viva de la virtud, ahora en la Era presente huyen del Artífice grande, y aun su sombra es las más veces ajada ignominiosamente de la ignorancia, mal principio para hacer blasón de su imágen. Dános ejemplo Los Antiguos en la unión y estimación de las Artes; pues en Grecia los Nobles usaban dellas, y no era permitido sino a ellos. En Roma también sabemos, que a los Caballeros les era prohibido usar ejercicios que no fuesen liberales; pero estas artes por ser nobles las usaban, por quien tomaron el renombre los Fabios, linaje Romano llustrisimo, según Plinio, de cuya Nobleza habla. Y Libio con grande excelencia, y Fabio Patricio Senador Romano de quien se delineaba la grandeza de sus pasados, el cual después de 
haber sido gran lurisconsulto, y Historiador, se llamó Fabio Pintor, y así se le puso en el Templo de la Salud, que él pintó en el año de la fundación de Roma de 450 y después fue Embajador del Pueblo Romano.

Usaron esta Arte Turpilio, Caballero Romano. Y Aterio Labeon después de haber sido Cónsul de la Provincia de Narbona. Quinto Pedio Nino, Triunfal, Consular coheredero, dado por lulio Cesar al Emperador Octaviano Augusto su sobrino siendo mudo, con consulta de Mesala, y aprobación del mismo Augusto, dice Plinio, que aprendió el Arte de la pintura. Nerón fue pintor, Claudio, fue pintor, Claudio Adriano, Marco Antonio, Aurelio Filósopho, Valentiniano, Alexandro Severo, y últimamente el Emperador Constantino Octavo, de quien se refiere, que habiendo sido echado del Imperio en el año de 918 se sustentó con la habilidad de pintor, y de Arquitecto.

$Y$ considerando, que en todas las obras de ingenio son lícitas las conferencias, pues en ellas consiste el conocimiento verdadero, por cuya razón el señor Rey D. Felipe III permitió en su Real Palacio al Comendador Don Tribucio (sic) Espanochi, Caballero del Abito de S. Iuan, Ingeniero Militar, Gentil-hombre de su Casa, concurriendo con él el Maestro mayor de sus Obras Reales, en que se delinearon en controversia pública varias proposiciones de Mathemáticas, práctica de prespectiva, Architectura Militar, y política, y por último se propusieron los reparos que convenian hacerse en la inundación de el rio Guadalquivir en el año de 1604. El señor Rey D. Sebastián, de orden de el Padre Fr. Luis de la Cámara, que vino de Roma a ser su Maestro, de la Sagrada Religión de la Compañía de lesus, dispuso academia en su Real Palacio de la Nautica, y Architectura. Los Atenienses sus mayores festejos eran las academias. Los Romanos en el principio de su gobierno pusieron su mayor cuidado en las disciplinas Mathemáticas, y Militares, y con el uso de sus academias aplicaron las Artes, y las ciencias. Ataulfo, Rey de España estableció academias de medicina, y Mathemáticas, poniendo un letrero en su primitiva escuela, que decía: Obliga la virtud à que la veneren.

El Rey Ludovico Onceno, Rey de Francia, teniendo noticia de la academia que se celebraba en Mompiller (sic) de Francia, donde salieron grandes Architectos Políticos, y Militares, que unos sirvieron en su Real Palacio, y otros en los Exércitos de Flandes; y obligado de tan ilustres Artífices, instituyó en Mompiller la Cáthedra de Mathemática, y Achitectura con salario público. $Y$ el Christianisimo Rey Francisco, en quien concurrió la virtud de amparar, y favorecer las Artes, haciéndolo con particular exceso, siendo públicas aquellas razones que dijo, que él bien podía armar Caballeros, pero que no podia hacer Artífices, ni Architectos. 
El señor D. Rey Felipe IV padre de V. Mag. que está en gloria, porque se mantenga la academia de Bruselas, hizo francos a ocho Académicos della de todas las cargas Brugeses (sic). $Y$ en Roma ay distintas academias además de la que su Santidad mantiene. $Y$ en nuestra Era el Christianisimo Rey de Francia las sustenta de todas las Artes, además de un Colegio que tiene en Roma, manteniendo los estudiantes de diferentes artes a su costa, y es público que tiene este Seminario por su particular utilidad, y todos los demás Pontentados de la Italia.

$Y$ destos principios Académicos han resultado las honras que son notorias en los Artífices pasados, que no fuera necesario referirlas a no estar tan sepultadas cuanto hoy se experimenta; pues juzgan muchos por Oficiales de manos a los que hacen Artes liberales, como a los mecánicos, sin hacer juicio de la excepción con que los han tratado los Principes con particular demostración, para que los Nobles las pudiesen ejercitar, como lo fue Michael Angel, a quien entre otras honras el Papa Pio IV le daba asiento. Y el Duque de Florencia, siendo su vasallo hacía lo mismo. A Alonso Berruguete, señor de la Ventosa, pintor, y Arquitecto, natural destos Reynos, le dió el señor Emperador Carlos $V$ la llave de su Cámara. Al Ticiano, y a León Leoni, los armó Caballeros en el Palacio de Bruselas. A Rubens, la señora Infanta Maria, le envió por Embajador Extraordinario a la Magestad del señor Rey D. Felipe IV (que está en gloria) padre de $\mathrm{V}$. Mag. Y siendo estos públicos y manifiestos ejemplares, sin otros muchos que han estado empleados en las Ordenes Militares; quando todas las Cortes de Europa se hallan con el adorno de academias públicas, en que a un mismo tiempo se ejercita virtuosamente la juventud, y resulta el bien universal, que se deja considerar, los juzgo por bastantes motivos para suplicar a V. M. sea servido de mandar que en conformidad de los ejemplares referidos, se le permita tener academia pública en Palacio, $u$ en donde $V$. M. mandare, en que se controviertan practicamente las Mathemáticas necesarias a la inteligencia tan util como cierta, que no puede ser perfecto Artifice en pintura, escultura, y arquitectura, en el que no concurrieran las líneas unidas con el dibujo, y se desengañen los que juzgan lo contrario, y se alienten los estudiosos a la continuación desta academia, y a un mismo tiempo tenga $V$. M. en semejantes líneas, como tan aficionado a las Artes un gustoso entretenimiento, y los Artífices a la sombra de tan soberano Monarcha, se dediquen al más dilatado estudio, para el mayor servicio de V. Magestad". 
